Session 2366

\title{
Integrated and Structured Project Environment in Mechatronics Education
}

\author{
Mark A. Minor, Sanford G. Meek \\ University of Utah \\ Department of Mechanical Engineering \\ 50 S. Central Campus Dr, Room 2202 \\ Salt Lake City, UT 84112 \\ minor@mech.utah.edu \\ meek@mech.utah.edu
}

\begin{abstract}
The Department of Mechanical Engineering at the University of Utah has developed a twosemester mechatronics course sequence at the third year that is required for all undergraduate mechanical engineering students. In addition to topics that are generally presented in most mechatronics courses; microcontroller use, sensors, actuators, and some electronics; we place a strong emphasis on mechanical system design that considers how design of that system will impact the instrumentation and control process. This provides a more holistic view of system design that emphasizes the implications of mechanical design decisions on system instrumentation and control. We require the students to practice this skill in a two-semester project activity while designing autonomous robots for an end-of-year competition. We have found that a structured design approach closely integrated with the course curriculum is critical for the timely success of the teams. In this paper we examine evolution of the structured design approach and robot themes based on projects from the last nine competitions. In this structured approach, the teams practice generating specific objectives, idea generation, concept selection, analysis and modeling, detailed design, manufacturing, and concept refinement. Initially during fall semester the teams focus primarily on the design and construction of the mechanical portion of their project while considering critical issues such as sensor and actuator placement and selection, and determining what role the micro-controller will play in the system. In spring semester, the robot is then completed by integrating the electronics, microcontroller, programming, and finishing touches to create an autonomous robot. Teams meet with course staff at these milestones to gain feedback and evaluate their progress. Throughout this process they witness directly the impact of their design and instrumentation decisions on the performance of their robot in a fun and competitive environment. The students are then better prepared for their fourth year capstone design project.
\end{abstract}

1. Introduction

Design is a skill often said to be best learned by experience. At the University of Utah, Mechanical Engineering students learn design by experience in this manner throughout the Proceedings of the 2002 American Society for Engineering Education Annual Conference \& Exposition Copyright " 2002, American Society for Engineering Education 
undergraduate curriculum via homework, lab experiences, and project assignments. These are intended to develop a meaningful understanding of the design process based upon a mixture of academic lessons and practical experience. A critical component of the design experience in our department is the third year where mechatronics is studied. Prior to this point, students have been educated in the use of CAD based design tools as well as standard and advanced manufacturing processes. The students possess the basic tools necessary for creating prototypes of their concepts and they are now ready in their third year to study and practice the design of integrated electro-mechanical systems: mechatronics.

The mechatronics curriculum marries traditional design of mechanisms with current tools for system integration: microprocessor applications, sensing and actuation techniques, systems modeling, and feedback control. This union facilitates the study of traditional subjects while providing a practical motivation for understanding the benefits and applicability of modern automation techniques. Such an understanding is crucial since mechanical engineers must frequently consider the design of a system or process that is subject to rigid constraints on cost, weight, space, and performance. All of these aspects are captured by the robotics project in the mechatronics course. The project itself is a critical component of the education because it forces the students to think beyond cookbook homework and lab experiments in order to create a successful robot. This emphasis on a substantial project experience is a common thread amongst mechatronics programs for many of the same reasons cited here. ${ }^{1,2,3,4}$ Our students also gain valuable first-hand experience striking the balance between design of an electro-mechanical system for a specific purpose versus the use of more flexible, and frequently costly, computer based automation tools. The importance of emphasizing mechanical system design while creating a mechatronic system is receiving similar attention elsewhere ${ }^{5,6}$ for the simple reason that we as mechanical engineers must realize the impact of our design decisions on system instrumentation and control.

In order to provide a project experience that involves all aspects of mechatronic system design, the project focuses on mobile robotic systems that must perform a specific task. Mobile robots are currently being used in many other curriculums $6,7,8,9,10$ with a wide variety of tasks and open-ended challenges. Similar to many of the robots in the literature, the tasks for our robots are sufficiently open-ended such that there are numerous approaches and solutions to the problem. Since our projects require significant design and system automation effort over the duration of the two-semester course sequence, a structured approach to design ${ }^{11}$ is necessary in order to assure the success of the teams. This approach is studied early in the mechatronics lecture sequence and the students are required to practice it while working on their projects. Evaluations of the projects are based upon the teams' abilities to satisfy predefined milestones as well as the capability and quality of their final robot at an end-of-year design competition. A more satisfactory design experience is gained by this structured approach and the students are more disciplined for their final year capstone design experience, which is typically based upon open-ended projects advised by mechanical engineering faculty.

In the sections that follow, we will discuss the current state of the mechatronics curriculum at the University of Utah and examine how the closely integrated project activity contributes to the understanding of electromechanical system design. We begin with a brief overview of the course content in Section 2 and proceed with consideration of the structured

Proceedings of the 2002 American Society for Engineering Education Annual Conference \& Exposition Copyright " 2002, American Society for Engineering Education 
project assignment in Section 3. Evolution of the project assignments used since 1995 is examined in Section 4 to illustrate evolution of the curriculum to its current state. This will be followed by a brief discussion of future improvements in Section 5, and concluding remarks and in Section 6.

\section{Course Content}

Undergraduate mechatronics education at the University of Utah is provided by a twosemester course sequence at the third year of the Mechanical Engineering program. The course is a fundamental component of the Mechanical Engineering design experience. Subject material includes mechanisms, sensors and actuators, micro-controllers, systems modeling, and feedback control. As typical of undergraduate curricula, lecture and homework assignments are used to build an understanding of fundamentals that are then reinforced by laboratory experiments and finally practiced in a course project. In order to maximize the perceived importance and relevance of the subject material, some topics are examined together. Mechanisms, sensors, actuators, and micro-controllers are typically examined together in the first semester of the class. Systems modeling and feedback control are then examined together in the second semester.

\subsection{Semester I: Mechanisms and Automation Tools}

Mechanisms, sensors, actuators, and micro-controllers are typically examined together in the first semesters of the course. This allows the students to consider the design of mechanisms with the viewpoint of actuating the mechanism and driving it to produce a desired output. The students are then able to recognize and consider various levels of automation that are best applied to different types of systems.

Laboratory experiments and the project are used in addition to homework to reinforce the aforementioned material. Laboratory experiments during the first semester of the course provide substantial experience with various types of sensors and computer control. Traditional sensors such as tachometers, potentiometers, and encoders are considered for accurate measurement of position. Less traditional sensors, such as infrared detectors, sonar modules, and electronic compasses, are studied for purposes of robot guidance. The National Instruments Lab Windows CVI software is used to develop an understanding of basic computer control and data acquisition capabilities. The MIT Handy Board ${ }^{12}$ micro controller is used for mobile robot control.

Experience with all of these tools, including the construction of electronic circuits for conditioning sensor signals, is practiced by all of the students in structured lab experiments. The traditional position measurement sensors are studied with application to a DC motor system via PC based data acquisition. The guidance sensors are calibrated and used to guide basic differentially driven CutieBot mobile robots via the Handy Board microcontroller. These robots were designed and built at the University of Utah specifically for laboratory experience in sensor calibration and motion control. This provides experience with robot guidance prior to the design and construction of the mobile robotics projects. The students are thus better suited to evaluate the capabilities of the sensors and determine how they should be incorporated into their own robots. 
During the first semester of the course, the project requires that the students design and build a prototype of the mechanical portion of their mobile robot. The project structure will be considered further in Section 3, but at this point it is important to note that the mechanical portion of the system requires careful consideration of sensors, actuators, and a preconception of what level of control will be applied. In contrast to the structured laboratory experience, the project is an open-ended, yet constrained, exercise in creating engineering solutions.

\subsection{Semester II: System modeling and control}

The second semester of the course focuses on systems modeling and feedback control. This is a natural transition considering that most of the mechanical systems discussed in Semester I will interface with a variety of mechanical, electrical, fluid, and thermal sub-systems. The subject material presented here allows the students to model the behavior of their systems and then control that behavior using the feedback control techniques. A unified modeling technique, linear graph theory ${ }^{13}$, is used for building system transfer functions and associated state equations. System response characteristics are studied and feedback control techniques are used to determine closed loop transfer functions, steady state error, stability, transient response, and frequency response. Homework, lab experiments, and the project augment lectures in this material.

In the lab we strive to provide a diverse experience in systems modeling and control that emphasizes the unified nature of mechatronic systems. Thus, systems from a variety of energy domains are studied. Thermoelectric heating of water is used to study first order system response, whereas second order transient response is studied by characterizing the response of a cantilever-mounted alpine ski subject to an initial displacement. The interaction of electromechanical systems is studied via DC motor experiments where the students characterize system parameters using a dynamometer. The students perform calibration, modeling, and instrumentation of the dynamometer. These results are then used to implement PID feedback controllers that demonstrate the impact of parameter variations on steady state error, system stability, and transient response. All of these experiments are performed using computer based data acquisition and control.

The project during Semester II focuses on refinement and automation of the mobile robot. Since the students had considered sensor and control strategies during Semester I, they must now implement their plan. They must integrate their sensors, micro controller, and electronics into the robot and program their strategy. These topics are considered further in Section 3, where the project is examined in greater detail.

\section{Mechatronics Project}

\subsection{Project theme}

The project is an extremely important component of the mechatronics course sequence. Lecture and lab together provide a very good understanding of the subject material, but they do not provide the creative experience of the project. The project deepens the students' understanding of the material by requiring them to apply the learned techniques to an open-ended

Proceedings of the 2002 American Society for Engineering Education Annual Conference \& Exposition Copyright " 2002, American Society for Engineering Education 
problem that most of them have not seen before: design of an autonomous mobile robot that must perform some task. Holding true to typical real world engineering challenges, the assignment typically has numerous potential solutions that must be considered in lieu of rigid constraints on cost, available space, maximum weight, actuator selection, power source, and micro controller capability.

The task and theme of the robot change annually, but an end-of-year competition is always the outcome of the project. The competition is conducted during the final week of classes in spring semester at the Mechanical Engineering Design Day. The ballroom at the Student Union is reserved for the public event. Nearly all undergraduates from the department are involved: the first year design class has a competition rooted in creative problem solving, the third year Mechatronics students conduct their competition and poster show, and the final year design teams present their projects in a poster session. High school and junior high school students are invited to the event and they usually participate in design activities such as bridge building or egg drop. News organizations typically attend and report on the department's students and projects. Hence, the students have had good opportunity to observe past competitions and they enter the course with definite anticipation of the project. This motivates the students to understand the material and take the project very seriously.

Given the competitive nature of the project, and the public venue where the competition is held, the students work very aggressively to create the most successful robotic system. At the start of the semester, the problem is posed to the class and the students first organize into design teams with four to five students per group. Project guidelines, constraints, competition rules, and available resources are clearly specified at the beginning of fall semester. Milestones and deadlines are closely integrated into the course in order to assure that teams progress with their designs in an orderly manner that coincides with course content and a structured design approach. This guides the students through the methodical design approach that is taught at the start of fall semester and helps to guarantee that educational and performance objectives of the project are satisfied.

\subsection{Structured Approach: Semester I}

Since the teams work on the project during both semesters of the course sequence, a structured design approach is necessary to assure that the teams use their time effectively. During Semester I, where mechanisms and automation tools are studied, the project is initially presented to the class. Project milestones are established throughout the semester to assure that a structured design approach ${ }^{11}$ is followed. The structure of these deadlines requires the students to generate specific objectives, brainstorm ideas, select concepts from these ideas, analyze and model their concept, create detailed designs, manufacture their prototype, and then present their results. A listing of these objectives and their placement throughout the semester is provided in Table 1. The key point of this process is that the teams must focus on design of automated mechanisms while considering the general configuration and performance objectives of the robot. Not only must the mechanism synthesize a desired motion, but it must also be capable of integrating with the rest of the robot. This means that the entire system must be considered from the start with a clear strategy that requires them to consider sensor strategies, micro-controller operation, actuator sizing, power source placement, etc.

Proceedings of the 2002 American Society for Engineering Education Annual Conference \& Exposition Copyright " 2002, American Society for Engineering Education 
To help guide the teams through the milestones, they meet with course staff at each step to discuss their progress and gain feedback. The teams select their advisor from amongst the course Teaching Assistants (TA) or the instructor. Throughout the semester, the teams are evaluated on how well they satisfy the milestones in a timely manner. The milestones are discussed during meetings with team advisors, which actually start during the fifth week of the course. Leading up to that point, the design process is discussed during the first week of the class and the project theme and guidelines are discussed during the second week. The teams must organize themselves by the end of Week 3 and be prepared to discuss their design concepts by the end of Week 5. This leaves ample time to cover many issues relevant to their machines prior to the first meeting at which the students propose their design concepts. Based upon feedback from the staff, the team will then analyze the concept further to determine its suitability and resolve details for implementation. These results are discussed during Week 7. By the end of Week 10, the team must discuss their full solid models and detail drawings with their advisor. This requires the students to take advantage of modern CAD tools to resolve space and operability considerations before going to the machine shop. Once these results are approved, the teams then proceed with manufacturing. There is one intermediate manufacturing milestone to check progress prior to the prototype completion during Week 15.

At the end of Semester I, the teams have designed and constructed the mechanical portion of the robot, which is typically actuated by geared DC motors. During Week 16, the teams then demonstrate their machine to the class and describe their results to conclude this part of the course. In this presentation, they are required to describe their specific objectives, mechanical design, analysis and expected performance, manufacturing, and actual performance. They also discuss any discrepancies between their actual and desired performance, as well as the revisions that they propose to improve their system. This helps the entire class learn about the solutions that the other teams have pursued as well as the success of those techniques.

Table 1. Milestones and objectives during Semester 1: Mechanisms and Automation Tools.

\begin{tabular}{|c|l|c|}
\hline$\frac{\text { Week }}{\underline{\text { Due }}}$ & Project Milestones and Objectives & $\underline{\underline{\text { Staff }}}$ \\
\hline 1 & Deeting & \\
\hline 2 & Project theme presented in class & \\
\hline 3 & Project teams organized (milestone) & Required \\
\hline 5 & Propose designs (milestone) & Required \\
\hline 7 & Analysis and modeling (milestone) & Required \\
\hline 10 & Detail design and solid modeling done (milestone) & Required \\
\hline 13 & Manufacturing progress update (milestone) & Required \\
\hline 15 & Prototype completed (milestone) & Required \\
\hline 16 & Present results to class & \\
\hline
\end{tabular}




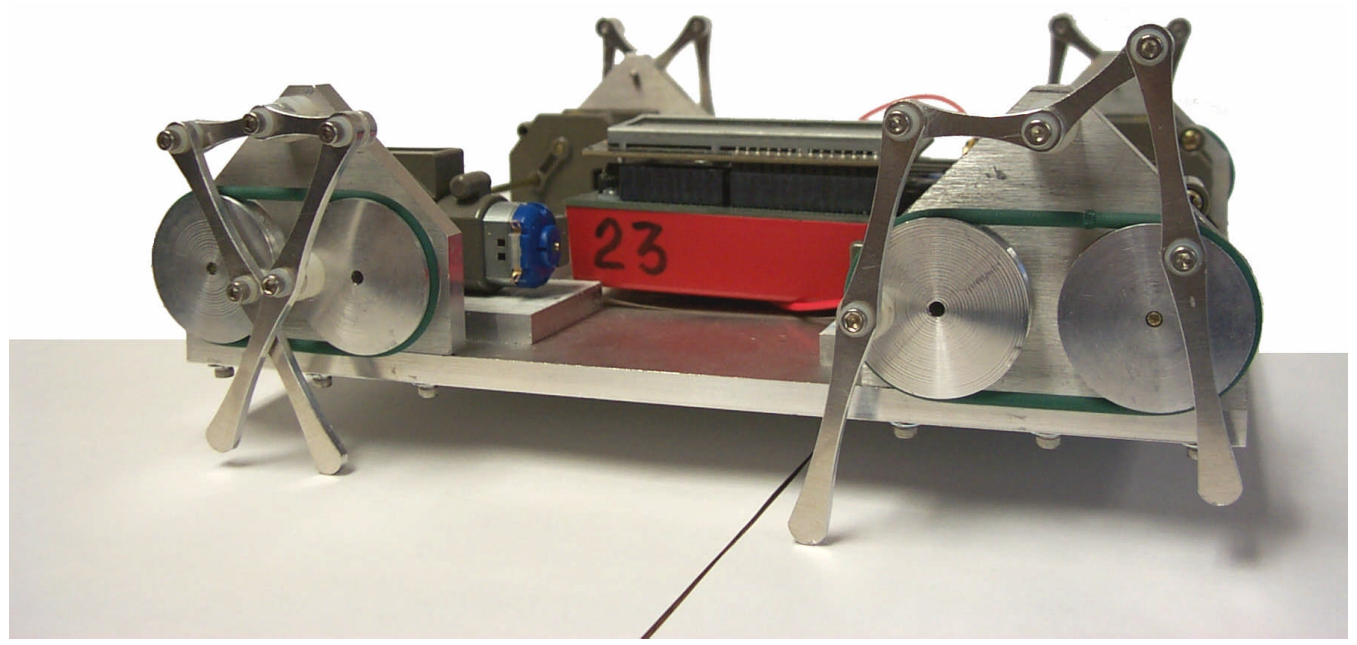

Figure 1. An example of a walking sumo wrestling robot (the Red Dog) at the completion of Part I. This walking machine is the creation of Jason Booth, Ben Hawkins, Eric Landis, Rob Preator, and Trent Wall. ${ }^{14}$

\subsection{Structured Approach: Semester II}

During Semester II of the course, the students work through milestones in order to complete the robot. As listed in Table 2, the first group of milestones requires the teams to complete their mechanical system. This includes refining their existing mechanical system and incorporating additional simple mechanisms as required. The teams must propose these changes during Week 2 and then demonstrate the performance of the system with these modifications during Week 6. Most teams must refine their mechanism, but learning about the necessity of iteration and improvement are valuable lessons of design.

Automation of the robot is the remaining focus of Semester II. The tasks include proposal and design of sensor schemes, integration of the microcontroller and sensor systems, proposal of the program structure, programming and debugging the system, and finally demonstrating the system prior to the competition. Similar to Part I, teams meet with course staff to discuss their progress and the teams are evaluated on their timely achievements. Milestones require the teams to propose their sensor and skin (a covering that protects and decorates the robot) designs during Week 5 and then review the CAD designs with these modifications integrated during Week 6. This again forces the teams to consider sensor placement and mounting in a solid modeling environment, as well as how the skin may effect sensor placement, all prior to manufacturing. By the end of Week 8 , the team must have incorporated the micro controller into the system and demonstrated its ability to control actuation of the mechanical portion of the robot. The program architecture is also discussed during Week 8 and by the end of Week 10 the team must demonstrate its ability to interface with the integrated sensory systems. By the end of Week 12 the robot must be completed, and by the end of Week 13 the teams must practice the competition as a demonstration for the staff. The teams compete at Design Day at the conclusion of Week 14, which is accompanied by a poster session. In the poster, each team must describe the design of their robot, its systems, and its analysis. The progress at each of the milestones as well as the final robot and poster session determine the teams' project grades for Semester II.

Proceedings of the 2002 American Society for Engineering Education Annual Conference \& Exposition Copyright ”2002, American Society for Engineering Education 
Table 2. Milestones and objectives during Semester 2: Systems Modeling and Control.

\begin{tabular}{|c|l|c|}
\hline$\frac{\text { Week }}{\text { Due }}$ & Project Milestones and Objectives & $\begin{array}{c}\underline{\text { Staff }} \\
\text { Meeting }\end{array}$ \\
\hline 2 & Propose revisions and modifications & Required \\
\hline 5 & Propose sensor and skin design & Required \\
\hline 6 & $\begin{array}{l}\text { Review sensor \& skin CAD designs, } \\
\text { Demo completed revisions }\end{array}$ & Required \\
\hline 8 & $\begin{array}{l}\text { Demonstrate micro-controller integration and usage, } \\
\text { Propose program structure }\end{array}$ & Required \\
\hline 10 & $\begin{array}{l}\text { Demonstrate sensor integration and usage, } \\
\text { Demonstrate program performance/progress }\end{array}$ & Required \\
\hline 12 & Robot completed & Required \\
\hline 13 & Practice competition & Required \\
\hline 14 & Competition and poster session & \\
\hline
\end{tabular}
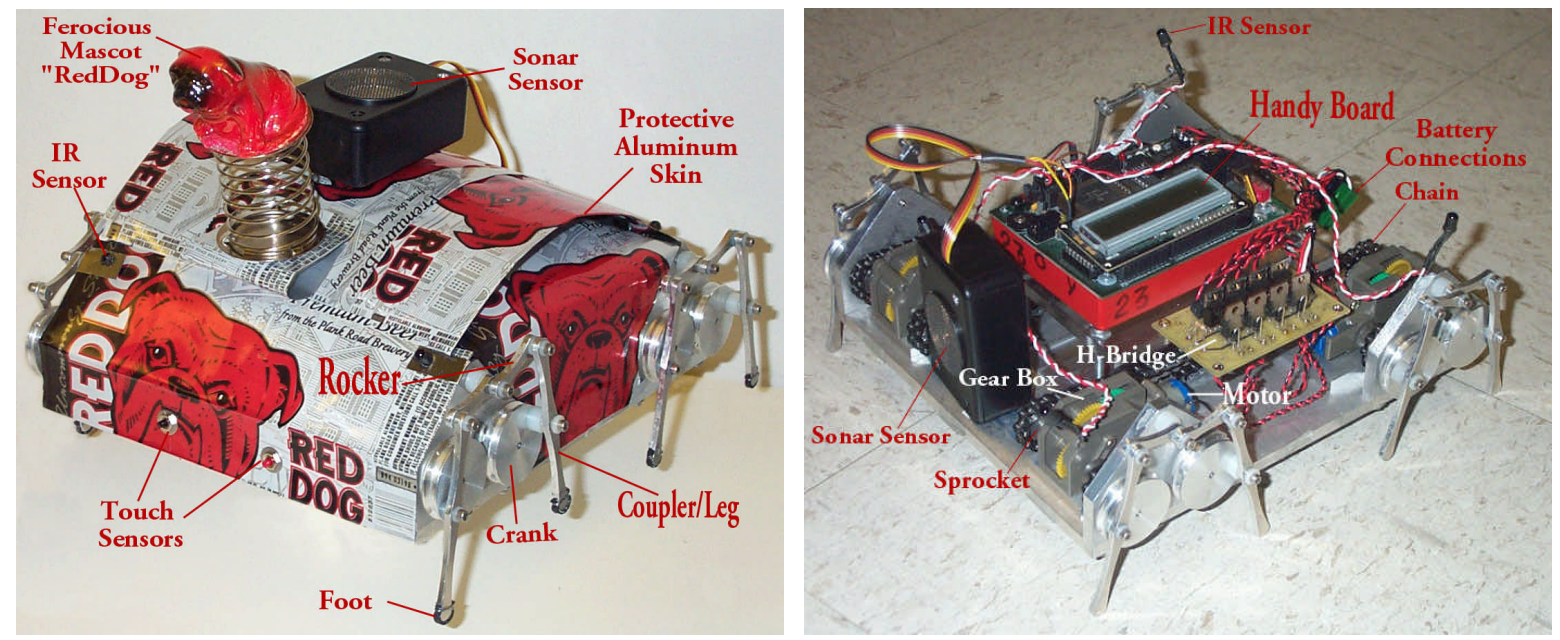

Figure 2. The Red Dog sumo wrestler at the end of Part II. It is shown here with and without its protective outter skin. ${ }^{14}$

4. Case studies: Development of Structured Projects

Throughout the last several years the project themes and the structure of the project itself have evolved. They have always focused on the design and control of a robotic system for an end-of-year competition, but the types of robots and the tasks that they perform have continuously changed. Likewise, the degree to which the project is structured and integrated into the course has matured as a result of the experiences with the past projects. In the following paragraphs, we will examine the evolution of the project activity from its conception as a loosely structured activity with little mechanical design to its current state as a tightly integrated mechatronic system design experience. 


\subsection{Project evolution}

In Summer 1995, first Mechatronics competition project was attempted in the department of Mechanical Engineering as part of a term-length (12 week) course focused on feedback control systems. The goal of the project was for the students to design controllers using a PC with data acquisition to make a serial link robot throw Nerf basketballs into a hoop. Infrared sensors, placed on the robot by the instructor, were used to locate an incandescent light over the basket. In this initial project, the primary focus was computer-based control and there was not any mechanical, sensory, or actuator design experience. The project was for all practical purposes, an end-of-semester capstone activity for control system design.

Mechanical design was an element of the project during the second competition. The theme was again basketball playing robots, but this time they were based on autonomous platforms with ball throwing mechanisms. The robots were controlled using an umbilical connected to a PC. During these first projects the students organized and paced themselves. This was in an attempt to let them discover the difficulties of team organization and project management. At the end of the first term, the students had to turn in a report describing their design for a ball throwing mechanism. Other than that, few milestones were required. Most of the teams, of course, waited until the last week to do most of the work. They were, however, very enthusiastic in building their robots working all day and night long to prepare for the competition.

The third project used Handy Board micro controllers to control differentially steered wheeled robots to track a black tape on the floor using infrared emitters (LED) and infrared sensors. Following the tape, the robots had to sort different weights and deliver them to the appropriate bins. During the first term, the teams designed and built the mechanism for the robot that weighed and lifted the objects. In the second term they built the mobile platform to support the Handy Board, sensors, lift mechanism, etc, and completed the automation of the system. Without the milestones though, we continued to find that the majority of the teams would procrastinate until the week before the final due date to build their robots.

During the fourth project we attempted to structure the project by requiring the teams to show progress midway through the semester. In this competition, sonar range finders were introduced on sumo wrestling robots in order to allow them to locate their opponent. A light source above the center of the ring allowed IR sensors on the robots to sense their position. At the competition, each robot attempted to push their opponent out of the ring or flip them over. The milestones were not sufficiently specific, though, and again most of the work was completed at the last minute.

In the fifth project the machines became more complex and the due dates were more specific. Based on a soccer theme, robots used sonar sensors to locate a ball and their opponent while attempting to kick a goal. Some teams designed encoders on magnetic compasses to help determine the correct direction for the goal. During the first semester, the teams designed mechanisms to pick up the ball and kick it into the goal marked with an incandescent bulb. The teams had to show that they could kick the ball during the first term. During the second term, they demonstrated that they could find the goal at the beginning of the term, using either IR

\footnotetext{
Proceedings of the 2002 American Society for Engineering Education Annual Conference \& Exposition
} Copyright "2002, American Society for Engineering Education 
sensors or a magnetic compass, and then midway through the term they demonstrated that they could find the ball with the sonar sensors. Two weeks before the competition, the teams had to demonstrate that their robot could find the ball and kick it into the goal without an opponent in their way. This more structured approach helped the teams produce better robots and reduced the level of last minute efforts at the end of the semester. The problem, however, was that teams were still proceeding in a more ad hoc approach in short bursts throughout the semester. While they accomplished their goals, they failed to learn the benefits of a structured design approach.

In the sixth project, the mechanical system was similar to the soccer robots of the previous project, but greater levels of autonomy and adaptability in robot behavior were explored. Hockey robots competed in teams of two in order to find a puck and attempt to score a goal. One robot was the goalie and the other the offensive player. It was not decided before the match which role the robot would play and each robot had a mechanism to hit the puck.

Electronic compasses were used to determine the direction of the goal and infrared sensors were used to locate the puck. More regimented milestones were defined where various parts of the robot mechanisms, sensors, and control were demonstrated throughout the year. This helped the teams to complete the robots in a timelier manner. There were still teams working day-and-night before the competition, but this was more due to trying to make their robots better and prettier. Many had well constructed bodies and paint schemes, Figure 3. The more structured milestones helped the teams break the robots into discrete subsystems that they could analyze and design more effectively.
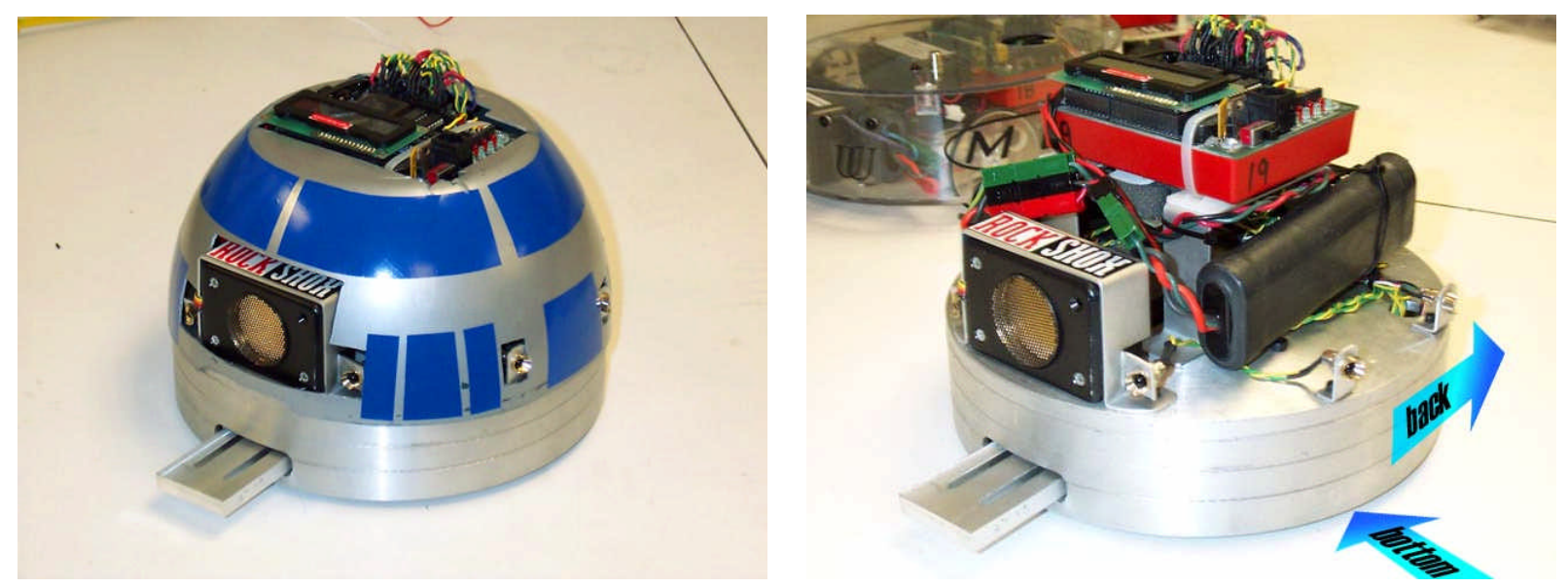

Figure 3. A hockey robot from the sixth year of the competion. Show with and without its protective skin. ${ }^{14}$

In the seventh year, biathlon robots tracked a tapeline through a course and shot pingpong balls at targets illuminated with an incandescent bulb. The mechanisms had to shoot and reload the ping-pong balls for each target. Similar to years past, the shooting mechanism was the focus of the first semester of the course and the mobile platform with automation was the focus of the second semester of the course. An example of a biathalon robot, is shown in Figure 4. 


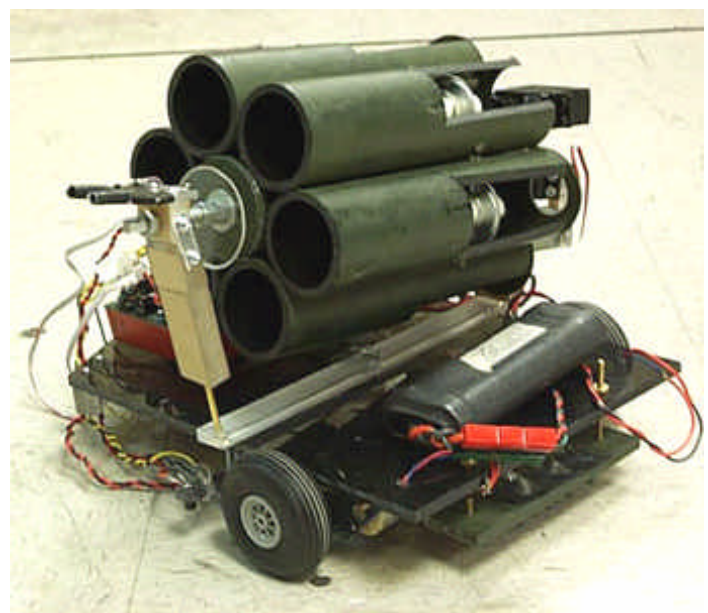

Figure 4. A completed biathalon robot from the seventh project. ${ }^{14}$

In the eighth project (last year), the sumo-wrestling theme was repeated, but the robots were required to use walking locomotion rather than wheels or tracks. In contrast to years past, the teams used Semester I of the course to design and manufacture the mobile part of the robot: the walking mechanism. The teams had to carefully consider what type of system would be used to synthesize walking and to what degree automation and control would be used in walking. The students were initially quite intimidated by this task, but a much more structured design approach was used to establish the milestones described previously in Section 3 (idea generation, analysis, detail design, prototyping, and refinement). As this was a more demanding design exercise, these milestones helped the teams complete the walking mechanisms in a timely manner, with a much smaller fraction of the teams reworking their robots at the last minute. During the second part of the course, a similar structured approach was used to refine the walking mechanisms, integrate the offensive measures, sensors, micro-controllers, and skin. Overall, the structured milestones helped the teams to get their robots done in a timelier manner and they also forced the teams to discuss their ideas with the course staff. Better feedback was achieved and the level of robot

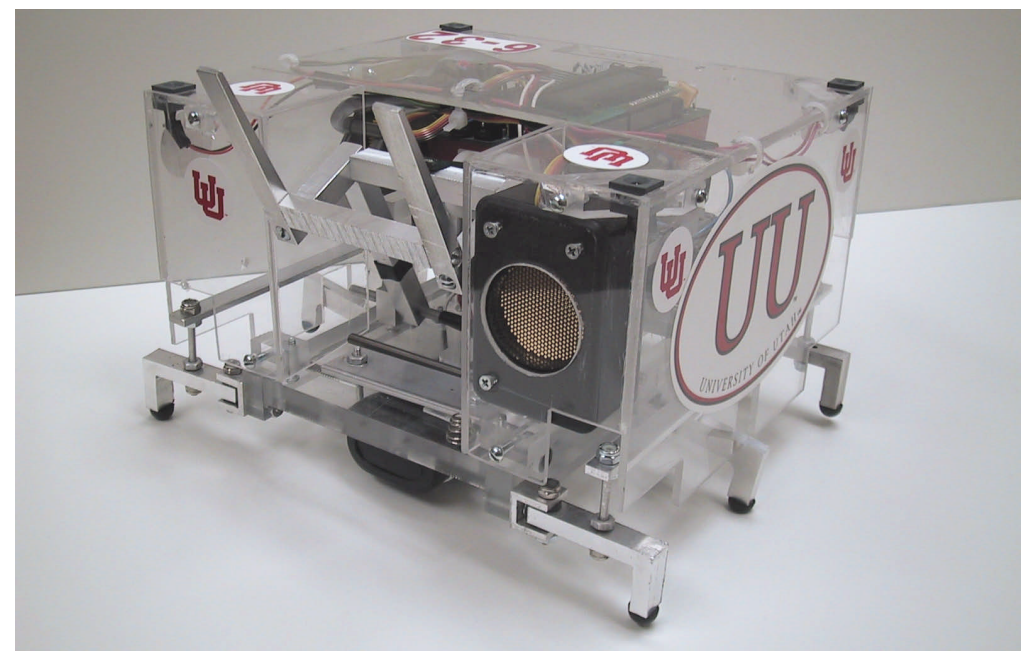

Figure 5. The winning walking sumo-wrestling robot from the eighth competition. ${ }^{\mathbf{1 4}}$ Proceedings of the 2002 American Society for Engineering Education Annual Conference \& Exposition Copyright " 2002, American Society for Engineering Education 
quality was improved despite a more demanding mechanical theme. The robot that won the competition is shown in Figure 5, while a competitor robot is shown at various stages of development in Figure 1 and Figure 2.

\subsection{Current Format}

This year, 2001-2002, is the ninth competition and a new more challenging mechanical theme is used: Jumping Robot Olympics. Each team must design and build a jumping robot to compete in three summer Olympic events during the Design Day competition: the high jump, the long jump, and a (modified) hurdle race. Similar to the real track and field events, the robotic athletes must jump up to and through the courses. Infrared sensors and magnetic compasses are available for guidance and sonar sensors can be used for determining obstacle or hurdle locations. Limit switches, potentiometers, and IR emitter/detector pairs are being used for sensing and controlling the jump mechanism.

The projects now have distinct milestones, Section 3, specified in the syllabi at the beginning of each semester. This has helped the students to better pace and organize their teams, and it has required them to see the need to 'lock-in' their design and pursue good manufacturing. Towards this objective, the teams are now required to design their robots in CAD software as solid models to assure proper fit and function, and many teams make the parts using numerical machine tools based on these models. In this particular competition, the teams must design and build the jumping mechanism of their robot during Semester I. As many teams have discovered the effects of friction, the first task during Semester II has been refinement of the mechanism, followed by sensor and microcontroller integration. The drive motors are restricted to hobby motors that are provided to the teams, which prevent an unfair advantage gained by a team that may have access to high power motors. The primary source for all of the power on the robot for all mechanisms and other devices must come from the battery packs provided.

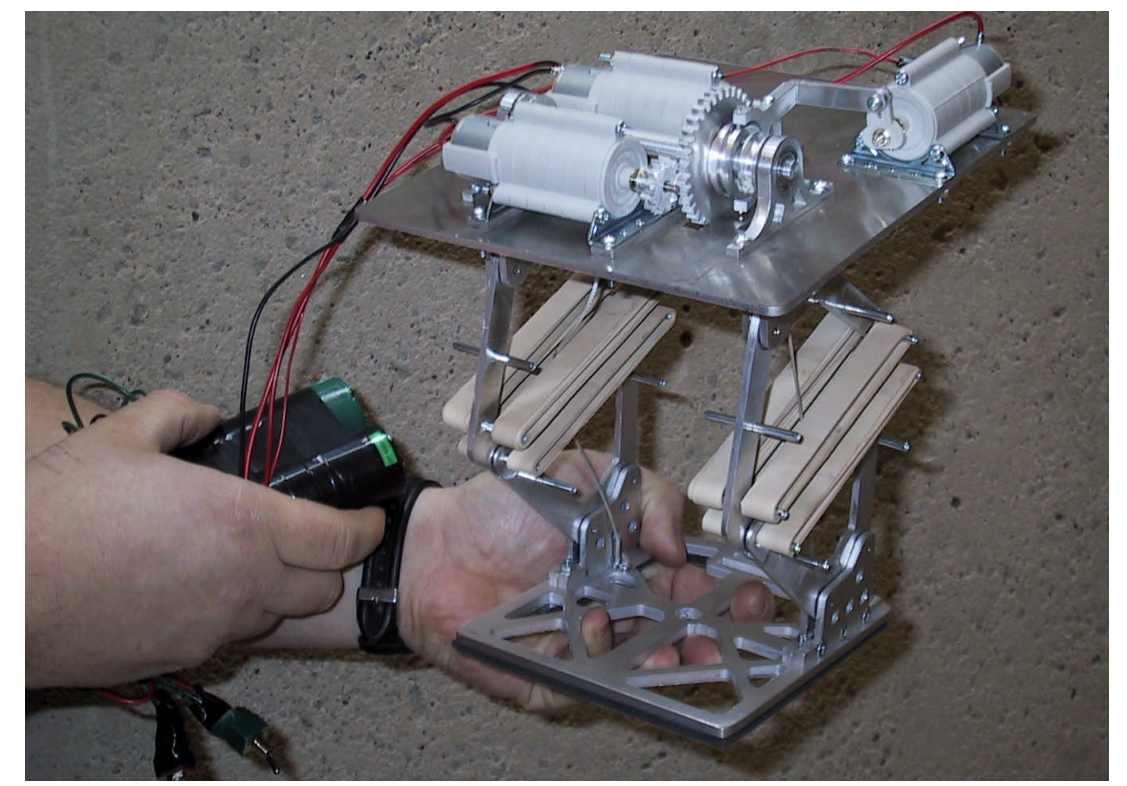

Figure 6. The jumping mechanism of a robot after completion of the first semester.

Proceedings of the 2002 American Society for Engineering Education Annual Conference \& Exposition Copyright ”2002, American Society for Engineering Education 
At the time of writing this paper, Part I of the project has been completed and Part II is well under way. An example of a successful jumping machine at the end of Part I is shown in Figure 6. We found that nearly all the groups had achieved their milestones, but not all of them were jumping as designed. This is largely due to the challenging task of building a jumping machine, which is highly susceptible to frictional power losses, poor actuator selection, or oversights in mechanism design. Most importantly, though, the teams are learning the valuable lessons of iteration and improvement by using the beginning of Part II to refine their machines. The remaining milestones for Part II follow those discussed in Table 2 exactly.

\section{Project Evaluation}

A secondary benefit of the structured and integrated approach to the design project is that it provides a larger set of metrics to evaluate the teams. Throughout both semesters, the teams are evaluated at each milestone while meeting with the course staff. The teams receive grades based upon their progress towards successfully satisfying the milestone. Deliverables, such as drawings, analysis, mechanisms, program code, etc., are typically brought to the meetings. These are discussed, reviewed, and graded based upon their ability to satisfy the milestone and provide the team with the capability to continue towards the next milestone. If a team fails to meet a milestone in a timely manner, they are penalized by $10 \%$ per week for that milestone until the deadline is completed. As discussed in the previous sections, the milestones during the first semester are based upon design and construction of the mechanical portion of the robot. In the Second Semester, the milestones are oriented towards refinement and automation of the robot. These milestones account for $30 \%$ of the project grade each semester.

A second metric used for evaluating the team projects is a presentation at the end of each semester. At the end of the first semester, each team presents their robot to the class in a tenminute presentation focusing on the mechanical design, supporting analysis, manufacturing, costs, and resulting performance. The teams are required to demonstrate their functioning system at the end of the presentation. Given the time limit, the presentations must be concise, well thought, and carefully rehearsed. It is, however, more than sufficient time for the class to learn about the diversity of techniques used by each team. A poster-presentation at the Mechanical Engineering Design Day concludes the second semester. The poster must describe the mechanical, actuator, sensor, and computational components of the robot and provide sufficient detail for educational value to the other participants of design day. The students are also required to attend their poster and answer any questions that spectators may have. During each semester, the presentation also accounts for $30 \%$ of the project grade.

The last metric used to evaluate the projects each semester is the completed robotic system itself. At the end of the first semester, the machines are evaluated based on their capability to perform the desired task (such as walking, jumping, throwing, etc), their quality of manufacturing, and the quality of their design. At the end of the second semester, the robots are graded on their capability to perform the desired tasks autonomously. This requires consideration of the sensor scheme, programming, mechanical systems, and the overall aesthetic quality and manufacturing. The robot grade accounts for $40 \%$ of the project grade each semester. 
The grading format just described encourages the teams to distribute their efforts throughout the entire semester while focusing on the quality and capability of their final product. The final presentation likewise requires the teams to summarize their efforts for their own benefit, as well as for the benefit of educating the entire class. Since the project is a time consuming and educating part of course, the project grade accounts for $20 \%$ of the final course grade each semester. The remaining portion of the course grade is distributed amongst exams, lab, and homework.

\section{Observations and improvements}

Despite the success of the structured and integrated project assignment, there are still issues that we would like to resolve. As the team activities have become more structured and disciplined, we have found that the team members themselves are becoming more proficient at the specialization of efforts. For example, each team seems to have a separate specialist for idea generation, machining, programming, CAD, etc. Since this is an educational project, this is fine as long as all the team members participate in each activity. All to often, though, we find that one team member may shoulder an entire task and the other teammates do not benefit from the exercise. In attempt to remedy this problem, we are incorporating certain fundamental education components of the project into the lab, which also provides the students with these skills prior to the project. The Cutie Bot robots are a prime example of this, since every student must learn to use sonar range finders, IR sensors, and the Handy Board for controlling the motion of differentially steered mobile robot. This is the first year to use these robots in lab and the students have been overwhelmingly receptive to the activity despite the level of effort that can be required when bugs show up in a program.

A second related problem that we would like to resolve is ability of the students to function effectively in teams. While this is just the opposite of the problem just mentioned, it is usually the result of one or more teammates not contributing, or one teammate being the "hero" and attempting to "rescue" a team with less motivated members. While we have attempted to account for this by grading the contributions of the individuals, it is not a resolution to the problem. In attempt to remedy this issue, we are as a department recognizing the necessity for team building skills and beginning to teach lessons in this area earlier in the curriculum.

Overall, we have found the structured and integrated Mechatronics project to be a very useful component of the Mechatronics course and design sequence. The students have continued to rise to the challenges that we set forth, and now we feel that they have a much better understanding of integrated system design and the structured approach to design. A key part of this education has been the course staff providing feedback to the teams during their milestones meetings, which would not be possible without quality TAs that truly understand system integration. In the past, our TAs have participated in building a robot, but typically they just do have time for this extra effort, despite its value.

\section{Conclusions}

A highly structured Mechatronics project environment focused on the design of autonomous mobile robots was examined in this paper. This structure has evolved over several 
years of teaching this course after realizing that the students need to be trained in structured design methodology. This structured environment provides numerous milestones that the teams must follow during the design and construction of their robotic systems. These milestones assure that the teams practice a structured design approach that is closely integrated into the lecture and lab activities. This provides the students with a stronger education in the design of integrated systems and forces them to practice their engineering skills in the process of designing and manufacturing their robots. We examine the project themes and evolution of this structured environment over the last several years in order to demonstrate its roots in the design of increasingly complex automated mechanical systems.

\section{Acknowledgements}

We would like to thank Santosh Devasia, currently with the University of Washington, for his contributions during the early development of this course and Robert Roemer, the department chair during this same initial period, for his support of this initiative.

\section{Bibliographic Information}

1. Krishnan, M., S. Das, and S.A. Yost, "Team-oriented, project-based instruction in a new mechatronics course." Proceedings of IEEE Computer Society Conference on Frontiers in Education, Champaign, IL, USA, 1999, Stripes Publishing L.L.C, p. 13D4/1-6 vol.3.

2. Carryer, J.E., "Undergraduate mechatronics at Stanford University." 1999 IEEE/ASME International Conference on Advanced Intelligent Mechatronics, Piscataway, NJ, USA, 1999, IEEE, p. 585-91.

3. Murray, W.R. and J.L. Garbini, "Mechatronics capstone design projects at the University of Washington." 1999 IEEE/ASME International Conference on Advanced Intelligent Mechatronics, Piscataway, NJ, USA, 1999, IEEE, p. 598-604.

4. Devasia, S. and S. Meek, "PC's and micro-controllers in mechatronics education." Technology-Based ReEngineering Engineering Education Proceedings of Frontiers in Education FIE'96 26th Annual Conference, New York, NY, USA, 1996, IEEE, p. 966-9 vol.2.

5. Kurfess, T.R., "Mechatronics and early mechanical design." 2001 IEEE/ASME International Conference on Advanced Intelligent Mechatronics. Proceedings. AIM '01, Piscataway, NJ, USA, 2001, IEEE, p. 990-3 vol.2.

6. Gardner, J.F., J.S. Lamancusa, and H.J. Sommer, III., "Mechatronics II: advanced mechatronics for mechanical engineering students." 1999 IEEE/ASME International Conference on Advanced Intelligent Mechatronics, Piscataway, NJ, USA, 1999, IEEE, p. 472-6.

7. Kaneda, T., et al., "Robotics-mechatronics education aimed to train a synthetic ability," Transactions of the Institute of Electrical Engineers of Japan, Part C, 1999. 119-C(3): p. 413-18.

8. Wyeth, G., "An introductory course in mechatronics: Robo-Cricket." Proceedings Fourth Annual Conference on Mechatronics and Machine Vision in Practice, Los Alamitos, CA, USA, 1997, IEEE Comput. Soc, p. 20-5.

9. Yamazaki, K., et al., "Development of a soccer-playing robot for ROBOCON '94: an example of hands-on education in mechatronics engineering, " International Journal of Engineering Education, 1996. 12(2): p. 100-14.

10. Bradbeer, R. and K.P. Rao, "Student-centred activity-based learning within a mechatronics degree course." International Conference on Recent Advances in Mechantronics. ICRAM '95, Istanbul, Turkey, 1995, Bogazici Univ, p. 247-54 vol.1.

11. Norton, R.L., Design of machinery: an introduction to the synthesis and analysis of mechanisms and machines. 2nd ed. 2001, Boston, Mass: McGraw-Hill.

12. Martin, F.G., Robotic Explorations: An introduction to engineering through design. 1st ed. 2001: Prentice Hall. 462.

Proceedings of the 2002 American Society for Engineering Education Annual Conference \& Exposition Copyright ”2002, American Society for Engineering Education 
13. Rowell, D. and D.N. Wormley, System Dynamics: An Introduction. 1997, Upper Saddle River, NJ: Prentice Hall.

14. Minor, M., S. Meek, and S. Devasia, Mechatronics Class Website. 2002.

\section{Biographical Information}

Mark A. Minor. Assistant Professor in Mechanical Engineering. B.S. from the University of Michigan. M.S. and PhD from Michigan State University. Teaching interests in mechatronics, controls, and design. Research interests include design and control of robotic systems for enhanced dexterity and superior mobility.

Sanford G. Meek. Assistant Professor in Mechanical Engineering. B.S. from Purdue, PhD. from University of Utah. Teaching interests are in mechatronics and controls. Research interests are in artificial arm control and bio-signal processing for prosthesis control. 